\title{
Web-based self-management with and without coaching for type 2 diabetes patients in primary care: design of a randomized controlled trial
}

\author{
Michael van Vugt ${ }^{1,2^{*}}$, Maartje de Wit ${ }^{1,2}$, Steven H Hendriks ${ }^{3}$, Yvonne Roelofsen ${ }^{3}$, Henk JG Bilo ${ }^{3,4}$
} and Frank J Snoek ${ }^{1,2}$

\begin{abstract}
Background: Self-management is recognized as the cornerstone of overall diabetes management. Web-based self-management programs have the potential of supporting type 2 diabetes patients with managing their diabetes and reducing the workload for the care provider, where the addition of online coaching could improve patient motivation and reduce program attrition. This study aims to test the hypothesis that a web-based self-management program with coaching will prove more effective on improving patient self-management behavior and clinical outcome measures than a web-based self-management program without coaching.
\end{abstract}

Methods: The effects of a web-based self-management program with and without coaching will be tested with a nested randomized controlled trial within a healthcare group in the Netherlands. In one year 220 type 2 diabetes patients will be randomized into an intervention group $(n=110)$ or a control group $(n=110)$. The control group will receive only the online self-management program. The intervention group will receive the online self-management program and additional online coaching. Participants will be followed for one year, with follow-up measurements at 6 and 12 months.

Discussion: The intervention being tested is set to support type 2 diabetes patients with their diabetes self-management and is expected to have beneficial effects on self-care activities, well being and clinical outcomes. When proven effective this self-management support program could be offered to other health care groups and their type 2 diabetes patients in the Netherlands.

Trial registration: Nederlands Trial Register NTR4064

Keywords: Type 2 diabetes mellitus, Self-management, Web-based, Asynchronized coaching

\section{Background}

Type 2 Diabetes Mellitus (T2DM) is a chronic metabolic disorder characterized by insulin resistance and beta-cell impairment [1]. Without proper treatment, T2DM can lead to long term complications such as neuropathy, nephropathy, retinopathy, cardiovascular disease, a poorer quality of life, and higher mortality rate [2]. The world prevalence of adults with diabetes in 2012 was estimated to be 371 million and is rapidly increasing [3]. In the Netherlands

\footnotetext{
* Correspondence: m.vanvugt@vumc.nl

'Department of Medical Psychology, VU University Medical Center,

Amsterdam, The Netherlands

${ }^{2} \mathrm{EMGO}+$ Institute for Health and Care Research, VU University Medical

Center, Amsterdam, The Netherlands

Full list of author information is available at the end of the article
}

this number was estimated to be 1 million in 2012 and is increasing with 70.000 patients per year. The number of T2DM patients is expected to rise to over 1.300 .000 in 2025 , of which more than $90 \%$ will have T2DM $[4,5]$. The treatment of T2DM demands lifestyle changes and additional medication. When insulin is required patients need to self-monitor their blood glucose levels. Selfmanagement is recognized as the cornerstone of overall diabetes management [6,7]. The Association of American Diabetes Educators (AADE) has defined 7 key selfmanagement behaviors important for T2DM patients: healthy eating, being active, monitoring, taking medication, problem solving, reducing risks and healthy coping [8]. To promote this daily self-management for T2DM patients, 
educational and behavioral support programs have been developed and shown to be effective in terms of behavioral and medical outcomes [7,9-12]. Similarly web-based selfmanagement programs have demonstrated improvements in health behaviors and health-related outcomes, and offer the possibility to increase both effectiveness and reach of clinical-based consultations [13-16]. Furthermore webbased self-management programs have the potential to decrease the workload of diabetes care providers. However it is unclear to what extent patients are motivated to use and adhere to online self-management programs. Face-to-face or telephone coaching can improve program adherence and online program effectiveness, both for medical and psychological outcomes. Moreover it can enhance satisfaction with the intervention [17-23]. To date, some studies that included coaching to their online T2DM self-management intervention showed improvements in dietary behavior, systolic blood pressure and a reduction in depressive symptoms [19,21,24-26] where as other studies found no effect $[27,28]$. However, the coaching in these studies targeted specific predefined health behaviors and instructions for diets and exercises. More flexible and adaptive style of coaching, attuned to the patients' own chosen specific goals and health behaviors (and consequently possible multiple health behaviors), would seem more appropriate. To our knowledge this has not been investigated yet in T2DM patients. It is therefore unknown what the effect is of online (asynchronized) individual coaching on multiple goals and health behaviors as chosen by the patient. To our knowledge we would be the first to test the effectiveness of adaptive online asynchronized coaching in a web-based self-management program.

\section{Aims}

We aim to test the hypothesis that self-management behaviors and biomedical outcomes improve in the group receiving an online self-management program with adaptive coaching versus those who don't receive additional adaptive coaching. We expect online coaching to have neutral or favorable effects on well-being, quality of life and satisfaction with care. We will test our hypotheses using an existing patient web-portal, which offers diabetes information and an overview of personal clinical outcome measures, supplemented with a self-management support program (SSP) [29]. The combination of the web-portal with SSP is referred to as an interactive care platform (ICP) and will be discussed in further detail below.

\section{Methods}

\section{Study design}

The current study design is nested within an ongoing cohort and intervention study, that focus on different constructs within the ICP [29]. We chose a two-arm nested randomized controlled trial (RCT) to test our hypotheses.
Measurements are scheduled at three points in time: at baseline, 6 months and 12 months after baseline. During first log-on to the ICP, 220 patients (see power calculation) will be randomized into two groups. These groups are: 1) patients receiving the ICP with additional online coaching in the SSP, 2) patients offered only the ICP without coaching in the SSP. A visual representation of the situation is shown in Figure 1. The medical ethical committee of the VU University Medical Center (certified by the Central Committee on Research involving Human Subjects in the Netherlands) approved the study protocol.

\section{Recruitment}

In line with the guidelines, the most patients in the care group are seen four times a year, of which one visit is the more extensive annual check-up. T2DM patients will be recruited when visiting their general practitioner (GP) or primary care nurse (PN) three months before the annual check-up. During their visit, PNs attend their patients to the existing studies, and to the availability of the ICP. After agreeing on participating in the studies and agreeing on using the ICP, patients receive a manual and login instructions for the ICP. During the first login to the ICP, patients are requested to provide additional informed consent.

\section{Study population}

The sample consists of people with T2DM who are treated in primary health care. The available sample pool consists of approximately $8300 \mathrm{~T} 2 \mathrm{DM}$ patients.

Inclusion criteria are: a diagnosis of T2DM, where the GP is defined as the main care giver; and aged $\geq 18$ years. Exclusion criteria for the RCT are: Mental retardation or psychiatric treatment for schizophrenia, organic mental disorder or bipolar disorder currently or in the past. Insufficient knowledge of the Dutch language to understand the requirements of the study and/or the questions posed in the questionnaires. Life expectancy $<1$ year due to malignancies or other terminal illnesses. Cognitive impairment, including dementia, which interferes with trial participation. Any condition that the Investigator and/or coordinating Investigator feel would interfere with trial participation or evaluation of results.

\section{Description of the intervention \\ Development of Interactive care platform}

For the creation of the ICP an existing patient web-portal was modified and merged with a SSP. This existing patient web-portal allows for a connection between health care practitioner and the patients, and allows patients to track their laboratory results as well as read personalized educational T2DM information online [29]. A SSP was developed and added to the patient web-portal to improve patients' self-management, promote empowerment and patient autonomy, and to counter attrition of the web-portal $[30,31]$. 


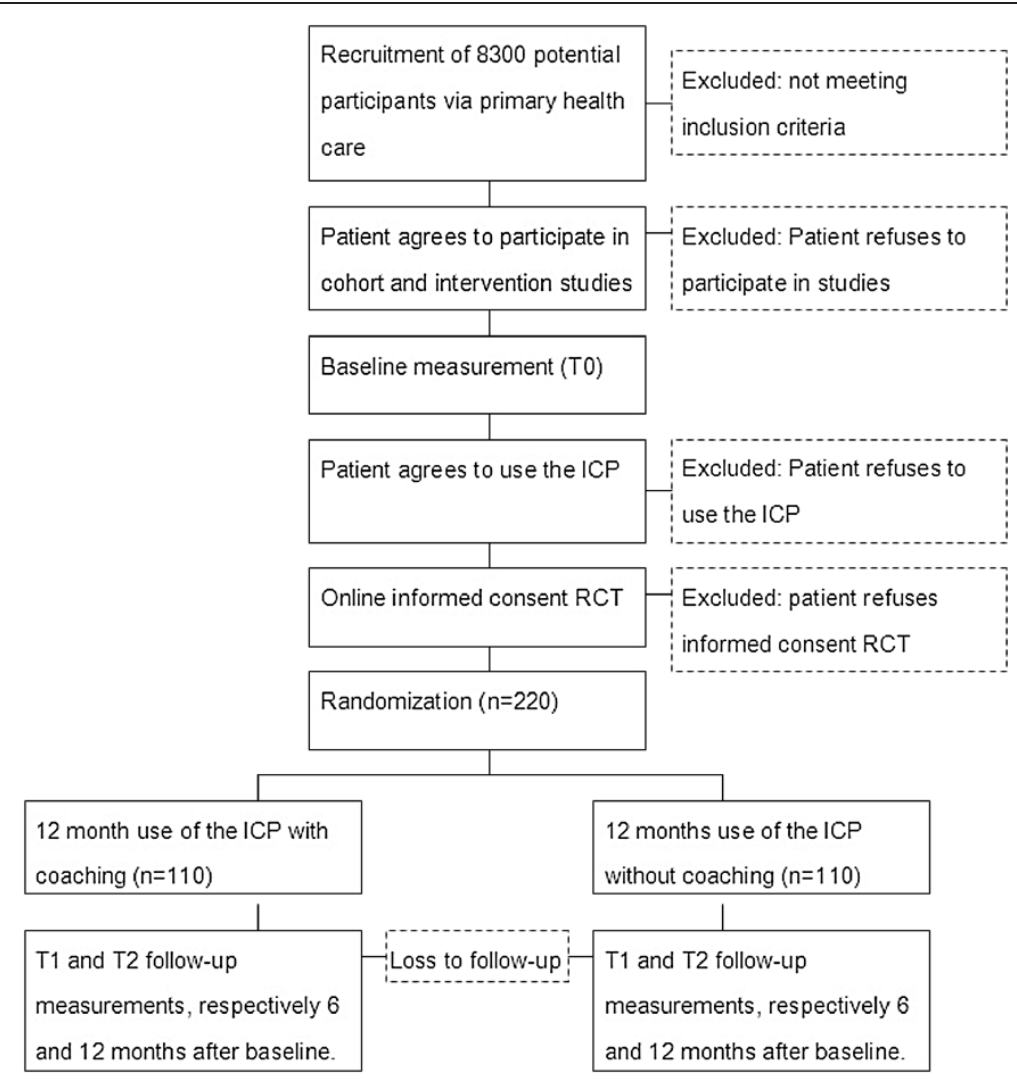

Figure 1 Flow chart of participants.

The development of the SSP was informed by a literature review and previous experience in developing and testing theory-based self-management programs for people with diabetes [21,32,33]. Additionally the development of the SSP was guided by the Health Action Process Approach (HAPA) model of behavior change. This model integrates key features of social-cognitive theories of behavior change, and has strong empirical evidence from studies in the prevention and management of chronic diseases, including diabetes [34]. The HAPA model identifies self-efficacy, outcome expectancy, and risk-awareness, as key determinants of intention formation (motivation), while goal setting and planning are crucial for bridging the intention-behavior gap, such as actual practice of desired health behaviors, which allows for the formation of behavioral maintenance. Self-efficacy is an important determinant throughout the different stages of behavior change, including maintenance, relapse prevention and relapse management. Table 1 provides an overview of the application of the HAPA model and behavioral change techniques as proposed by Michie et al. (2011), as guidance for developing the SSP [35].

Content for the SSP was also partly derived from the successful PRISMA (PRoactive Interdisciplinary SelfManagement) course, adapted by the VU University Medical Center for T2DM patients, which is based on the
DESMOND-program developed in the United Kingdom [36-40]. In PRISMA patients are encouraged to set personal goals and formulate a realistic action plan that is then followed during routine clinical encounters with the diabetes care provider. Patients are prompted to monitor and evaluate their goals and behaviors, and make adjustments accordingly [36-39,41].

\section{Self-management support program description}

The ICP offers personalized information about one's health status and educational modules that will inform the patient about risks related to specific behavioral and physical aspects derived from the collected personal clinical outcome data (HAPA: Risk-awareness). Furthermore within the SSP patients are stimulated to compare their personal clinical health outcomes to the GP's advice and are triggered to think of ways to improve their health status. Additionally they receive information about relevant health related behaviors for improving these clinical outcomes (HAPA: Self-efficacy and Outcome expectancy). Based on this information, patients can choose behavioral goals derived from 4 of the 7 self-management behaviors defined by the AADE (diet, exercise, medication \& stop smoking) where the other 3 defined self-management behaviors are integral part of the web-portal. In addition patients can 
Table 1 Application of the HAPA model and behavioral change techniques used for the SSP development

\begin{tabular}{|c|c|c|}
\hline HAPA model component & Components used in the SSP & Used behavioral change techniques \\
\hline \multirow[t]{8}{*}{$\begin{array}{l}\text { Risk awareness, outcome-expectancy, } \\
\text { self-efficacy }\end{array}$} & \multirow{2}{*}{$\begin{array}{l}\text { - Information and education about T2DM in } \\
\text { general and personalized to patients' current } \\
\text { health situation. }\end{array}$} & $\begin{array}{l}\text { - Provide information on consequences } \\
\text { of behavior in general/to the individual }\end{array}$ \\
\hline & & - Model/Demonstrate the behavior. \\
\hline & - Overview of patients' personal clinical results. & $\begin{array}{l}\text { - Prompt self-monitoring of behavioral } \\
\text { outcome. }\end{array}$ \\
\hline & $\begin{array}{l}\text { - Patients' clinical measures are compared to } \\
\text { norm values and GPs' advice, showed in a } \\
\text { table and in a graph. }\end{array}$ & - Prompt review of outcome goals. \\
\hline & \multirow{3}{*}{$\begin{array}{l}\text { - Information about the clinical measurements } \\
\text { and information on behaviors that influence } \\
\text { these clinical measurements. }\end{array}$} & $\begin{array}{l}\text { - Provide information on consequences } \\
\text { of behavior in general/to the individual }\end{array}$ \\
\hline & & $\begin{array}{l}\text { - Provide instruction on how to perform } \\
\text { the behavior. }\end{array}$ \\
\hline & & - Model/Demonstrate the behavior. \\
\hline & $\begin{array}{l}\text { - Patients can fill-in a motivation why they } \\
\text { want to change their behavior. }\end{array}$ & - Motivational interviewing. \\
\hline Goal setting & $\begin{array}{l}\text { - Patients are guided to choose a goal from } \\
\text { a list of } 4 \text { behavioral goals (diet, exercise, } \\
\text { medication \& stop smoking) }\end{array}$ & - Goal setting (behavior). \\
\hline \multirow[t]{6}{*}{ Action planning, Self-efficacy } & \multirow{4}{*}{$\begin{array}{l}\text { - Patients are guided to create a behavioral } \\
\text { action-plan for the chosen goal. (Patients } \\
\text { receive instructions and examples of } \\
\text { action-planning in the SSP). }\end{array}$} & - Action planning. \\
\hline & & $\begin{array}{l}\text { - Provide instruction on how to perform } \\
\text { the behavior. }\end{array}$ \\
\hline & & - Facilitate social comparison. \\
\hline & & - Set graded tasks. \\
\hline & $\begin{array}{l}\text { - Intervention group only: Patients' action-plan } \\
\text { is send to a coach for feedback. The coach } \\
\text { provides feedback (message in the SSP) on } \\
\text { the process of action-planning, not on medical } \\
\text { subjects. After receiving the feedback, patients } \\
\text { are prompted to start the planned behavior. }\end{array}$ & - Provide feedback on performance. \\
\hline & $\begin{array}{l}\text { - Patients are prompted to start the planned } \\
\text { behavior. }\end{array}$ & - Use of follow-up prompts. \\
\hline \multirow[t]{9}{*}{ Self-efficacy, Maintenance } & \multirow{2}{*}{$\begin{array}{l}\text { - Patients receive reminders and encouragements } \\
\text { via text-messaging and e-mail. }\end{array}$} & - Use of follow-up prompts. \\
\hline & & - Relapse prevention. \\
\hline & \multirow{4}{*}{$\begin{array}{l}\text { - Patients receive a reminder to return to the } \\
\text { ICP and evaluate their action plan. }\end{array}$} & - Set graded tasks. \\
\hline & & - Barrier identification/problem solving. \\
\hline & & - Use of follow-up prompts. \\
\hline & & - Provide feedback on performance. \\
\hline & \multirow[t]{2}{*}{$\begin{array}{l}\text { - Patients can fill in outcome measurements } \\
\text { in the ICP }\end{array}$} & $\begin{array}{l}\text { - Prompt self-monitoring of } \\
\text { behavior/behavioral outcome. }\end{array}$ \\
\hline & & $\begin{array}{l}\text { - Prompt review of behavioral } \\
\text { goals/outcome goals. }\end{array}$ \\
\hline & $\begin{array}{l}\text { - Intervention group only: Patients can ask } \\
\text { for feedback from a coach. }\end{array}$ & - Provide feedback on performance. \\
\hline
\end{tabular}

compose self-chosen action plans to support these goals (HAPA: goal setting and planning). Patients receive automatic reminders and encouragements while they carry out their planned actions. Eventually patients are prompted to evaluate their behavioral goals and action plans, based on graded tasks and barrier identification with help from the SSP. After the evaluation, patients are encouraged to restart the behavioral goal setting and action planning (HAPA: maintenance loop).

\section{Intervention group}

Hundred and ten randomized patients are offered the ICP with additional online (asynchronized) coaching to receive feedback on behavioral goals, action plans and evaluation 
of the executed health behaviors. These goals and planned health behaviors are chosen by the patient. The coaches follow a protocol where they serve as facilitator, and focus on process to specify action plans and let patients think for themselves. Coaches refrain from advising the patient with regard to medication or medical tests and refer to the GP if the patient requests such medical advice. After the patient has executed the planned health behaviors, the coach can support the patient by offering constructive and empowering feedback on the process of behavior change based on the HAPA model. Coaching will be carried out by trained master health-sciences students, by using asychronized messaging within the ICP. Feedback will be given on workdays within 48 hours after initial patient request.

\section{Control group}

The remaining 110 randomized patients will receive the ICP without additional coaching.

\section{Outcome assessment}

\section{Primary outcome measures}

Our ambition is to improve patients' self-care activities, as measured with the Summary of Diabetes Self-Care Activities (SDSCA) questionnaire [41].

\section{Secondary outcome measures}

Diabetes distress will be assessed using the Problem Areas In Diabetes care (PAID) survey, 5-item version [42].

Emotional well-being: The five items (WHO-5) questionnaire covers positive mood, vitality and general interests and has clinical use as depression screening [43,44]. Health-related Quality of Life (HRQoL) is tested by using the EQ-5D questionnaire $[45,46]$.

Health status: A selection of collected data during the regular yearly check-up will be included in the research to objectify a person's health status. This includes the following parameters: glycemic control (HbA1c), Body Mass Index (BMI), systolic blood pressure, diastolic blood pressure, cholesterol and smoking status.

Medical care: For all participants in the study the actual medical care utilization and use of medication will be documented using the following parameters: number of encounters with care providers, number of hospitalizations, use of medication (based on prescribed medication) and patient profile data.

ICP use during the study period will be measured using: number of log-ons, time spent per session, number of educational modules taken, number of coaching feedback received, number of goals set and adjusted.

\section{Statistical analyses}

Analyses will be conducted by using SPSS and Stata software. Normally distributed data will be presented as means and standard deviation, otherwise as median and interquartile range. Dichotomous/categorical data will be presented as numbers and percentage of total. After one year, the group of patients in the RCT who received additional coaching will be compared to the group of patients in the RCT who used the ICP without coaching on primary outcome, i.e. self care activities total score. To evaluate differences in target variables within and between groups over time we will use a linear mixed model for repeated measures (after 6 and 12 months). Baseline variables will be used as covariates. Analyses will be based on Intention-to-treat. Longitudinal linear regression, using Generalized Estimation Equations (GEE) will be used to investigate the differences between the two groups on primary (self-care activities) and secondary outcome variables over time. With GEE the relationships between the variables at different time-points are analyzed simultaneously, reflecting the relationship between the longitudinal development of the outcome variables and the longitudinal development of the predictor variables. GEE adjusts for the correlation between repeated observations taken in the same patient and has the advantage of handling longitudinal data on subjects with varying numbers of unequally spaced observations. The latter is important, because the assessments are scheduled within routine care and as a consequence, the time between the consultations can differ. Multi-level analyses will be applied to correct for the different primary care groups. All analyses will be corrected for baseline values, gender and age.

\section{Sample size calculation}

Change in self-care behavior is the primary endpoint as measured by the SDSCA total score. The study of Thoolen et al. was used as reference [47]. Sample size calculations indicate that a sample of 131 patients is sufficient to demonstrate an effect size of 0.30 at a significance level of $5 \%$ with a power of $80 \%$. Given an expected drop out rate of $20 \%$, we will include at least 220 patients in our RCT, 110 patients in each group.

\section{Discussion}

\section{Strengths and limitations}

Integrating the ICP in routine primary care for T2DM patients, adds to the external validity of the study. Primary care physicians can use the intervention as support for the standard treatment of T2DM patients. Health care professionals play an active roll in recruiting, informing and motivate patients for using the ICP. By doing so, people who are unmotivated and who would initially not consider using an ICP could be recruited, which can further increase external validity. With the integration of the ICP in standard primary diabetes care, we hope to reduce attrition, which is a known problem for web-based interventions [48]. With the use of reminders and online 
contact between participants and coaches we hope to limit attrition rates.

The flow of patients in this study is limited by the three different informed consents and agreements patients have to sign before they can be randomized for the RCT. This can create a bias of including only highly motivated patients in the RCT study.

The study participants will consist of primarily older patients who may be lacking computer skills which could have affect participation and attrition rates of the intervention.

In the current study proposal, the measurements will be executed at baseline, 6 months and 12 months after baseline. Therefore long-term effects of the web-based intervention cannot be measured.

\section{Future implementation}

The developed ICP is currently being tested in primary diabetes care setting. Having the support of a major Dutch insurance company increases the chances of the intervention being set out to other primary health care groups. Additional primary health care groups have already showed interest in using the ICP.

\begin{abstract}
Abbreviations
AADE: Association of American diabetes educators; BMl: body mass index; EQ-5D: EuroQol - 5 dimensions; GEE: Generalized estimation equations; GP: General practitioner; HAPA: Health action process approach; HRQOL: Health related quality of life; ICP: Interactive care platform; PAID-5: Problem areas in diabetes 5 questions; PN: Primary care nurse; RCT: Randomized controlled trial; SDSCA: Summary of diabetes self-care activities; SSP: Self-management support program; T2DM: Type 2 diabetes mellitus; WHO-5: WHO five item measure of well being.
\end{abstract}

\section{Competing interests}

This study was funded by the foundation Health Within Reach (Zorg Binnen Bereik). The foundation has no role in writing or publication of this manuscript. They also have no role in study design, data collection, data analysis or reporting of study results. All authors declare that they have no competing interests.

\section{Authors' contributions}

MvV and MdW are researchers in this project and mainly drafted this manuscript, furthermore they developed the SSP that has been added to the $I C P$. YR and SH are other researchers in this project and helped to draft this manuscript. They were involved in the development and study of the original web-portal which was later transformed to the ICP. FJS and HJGB conceived the involved studies and participated in its design and coordination and helped to draft the manuscript. All authors read and approved the final manuscript.

\section{Acknowledgements}

This study was funded by the foundation Health Within Reach (Zorg Binnen Bereik). We thank health care group HZDM for referring their patients to our study. We thank Juriaan Kok who provides coordinating services on behalf of the 'Kenniscentrum ketenzorg'.

\section{Author details}

'Department of Medical Psychology, VU University Medical Center, Amsterdam, The Netherlands. ${ }^{2}$ EMGO + Institute for Health and Care Research, VU University Medical Center, Amsterdam, The Netherlands. ${ }^{3}$ Diabetes Centre, Isala Clinic Sophia, Zwolle, The Netherlands. ${ }^{4}$ Department of internal medicine, University Medical Center Groningen, Groningen, The Netherlands.
Received: 11 November 2013 Accepted: 14 November 2013

Published: 16 November 2013

\section{References}

1. Gerich JE, Smith TS: b-cell defects and pancreatic abnormalities in type 2 diabetes. In Textbook of diabetes. 3rd edition. Edited by Pickup JC, Williams G. Oxford: Blackwell Publishing; 2003:23.1-23.11.

2. Cruickshank K, Beith C: Mechanisms in chronic diabetes. In Textbook of diabetes. 3rd edition. Edited by Pickup JC, Williams G. Oxford: Blackwell Publishing; 2003:46.1-47.1.

3. International Diabetes Federation: IDF Diabetes Atlas. 5th edition. Brussels, Belgium: International Diabetes Federation; 2011. http://www.idf.org/ diabetesatlas.

4. Baan CA, van Baal PHM, Jacobs-van der Bruggen M, Verkley H, Poos MJJC, Hoogenveen RT, Schoemaker CG: Diabetes mellitus in the Netherlands: estimate of the current disease burden and prognosis for 2025. Ned Tijdschr Geneeskd 2009, 153:A580.

5. Bilo HJ, Houweling ST: Toename van het aantal mensen met diabetes mellitus: noodzaak van een deltaplan. Ned Tijdschr Geneeskd 2009, 153:1048.

6. Clement S: Diabetes self-management education. Diabetes Care 1995, 18:1204-1214.

7. Norris SL, Lau J, Smith SJ, Schmid CH, Engelgau MM: Self-Management education for adults with type 2 Diabetes A meta-analysis of the effect on glycemic control. Diabetes Care 2002, 25:1159-1171.

8. Funnell MM, Brown TL, Childs BP, Haas LB, Hosey GM, Jensen B, Maryniuk M, Peyrot M, Piette JD, Reader D: National standards for diabetes self-management education. Diabetes care 2009, 32:S87-S94.

9. Deakin T, McShane CE, Cade JE, Williams RD: Group based training for self-management strategies in people with type 2 diabetes mellitus. Cochrane Database Syst Rev 2005, 2. CD003417.

10. Heinrich E, Schaper NC, de Vries NK: Self management interventions for type 2 diabetes: a systematic review. Eur Diab Nurs 2010, 7:71-76.

11. Norris SL, Engelgau MM, Narayan KV: Effectiveness of self-management training in type 2 diabetes a systematic review of randomized controlled trials. Diabetes Care 2001, 24:561-587.

12. Steinsbekk A, Rygg LO, Lisulo M, Rise MB, Fretheim A: Group based diabetes self-management education compared to routine treatment for people with type 2 diabetes mellitus. A systematic review with meta-analysis. BMC Health Serv Res 2012, 12:213.

13. Brown $L L$, Lustria ML, Rankins J: A review of web-assisted interventions for diabetes management: maximizing the potential for improving health outcomes. J Diabetes Sci Technol 2007, 1:892-902.

14. Glasgow RE, Bull SS, Piette JD, Steiner JF: Interactive behavior change technology. Am J Prevent Med 2004, 27:80-87.

15. Pal K, Eastwood SV, Michie S, Farmer AJ, Barnard ML, Peacock R, Murray E: Computer-based diabetes self-management interventions for adults with type 2 diabetes mellitus. The Cochrane Library 2013.

16. Ramadas A, Quek KF, Chan CKY, Oldenburg B: Web-based interventions for the management of type 2 diabetes mellitus: a systematic review of recent evidence. Int J Med Inform 2011, 80:389-405.

17. Barrera M Jr, Glasgow RE, Mckay HG, Boles SM, Feil EG: Do Internet-based support interventions change perceptions of social support?: An experimental trial of approaches for supporting diabetes self-management. Am J Comm Psychol 2002, 30:637-654.

18. Joseph DH, Griffin M, Hall RF, Sullivan ED: Peer coaching: an intervention for individuals struggling with diabetes. Diabetes Educ 2001, 27:703-710.

19. Mckay HG, Glasgow RE, Feil EG, Boles SM, Barrera M: Internet-based diabetes self-management and support: initial outcomes from the diabetes network project. Rehabil Psychol 2002, 47:31-48.

20. Ruggiero L, Moadsiri A, Butler P, Oros SM, Berbaum ML, Whitman S, Cintron $D$ : Supporting diabetes self-care in underserved populations a randomized pilot study using medical assistant coaches. Diabetes Educ 2010, 36:127-131.

21. van Bastelaar KM, Pouwer F, Cuijpers P, Riper H, Snoek FJ: Web-based depression treatment for type 1 and type 2 diabetic patients a randomized, controlled trial. Diabetes Care 2011, 34:320-325

22. Whittemore R, Melkus GD, Sullivan A, Grey M: A nurse-coaching intervention for women with type 2 diabetes. Diabetes Educ 2004, 30:795.

23. Wolever RQ, Dreusicke M, Fikkan J, Hawkins TV, Yeung S, Wakefield J, Duda L, Flowers $P$, Cook C, Skinner E: Integrative health coaching for patients with type 2 diabetes a randomized clinical trial. Diabetes Educ 2010, 36:629-639. 
24. Glasgow RE, Toobert DJ: Brief, computer-assisted diabetes dietary selfmanagement counseling: effects on behavior, physiologic outcomes, and quality of life. Medical care 2000, 38:1062-1073.

25. Glasgow RE, Boles SM, Mckay HG, Feil EG, Barrera M Jr: The D-Net diabetes self-management program: long-term implementation, outcomes, and generalization results. Prevent Med 2003, 36:410-419.

26. McTigue KM, Conroy MB, Hess R, Bryce CL, Fiorillo AB, Fischer GS, Milas NC, Simkin-Silverman LR: Using the internet to translate an evidence-based lifestyle intervention into practice. Telemed e-Health 2009, 15:851-858.

27. Dale JR, Williams SM, Bowyer V: What is the effect of peer support on diabetes outcomes in adults? A systematic review. Diabet Med 2012, 29:1361-1377.

28. Glasgow RE, Christiansen SM, Kurz D, King DK, Woolley T, Faber AJ, Estabrooks PA, Strycker L, Toobert D, Dickman J: Engagement in a diabetes self-management website: usage patterns and generalizability of program use. J Med Internet Res 2011, 13:e9.

29. Roelofsen $Y$, Hendriks S, Sieverink F, van Vugt M, van Hateren KJJ, Snoek FJ, de Wit M, Gans ROB, Groenier KH, van Gemert-Pijnen JEWC, Kleefstra N, Bilo HJG: Use and effects of an interactive online care platform in patients with type 2 diabetes: design of the e-Vita diabetes mellitus study (e-VitaDM-1/ZODIAC-40). Bethesda (MD): National Library of Medicine (US); 2002. http://clinicaltrials.gov/ show/NCT01570140.

30. Greenhalgh T, Hinder S, Stramer K, Bratan T, Russell J: Adoption, non-adoption, and abandonment of a personal electronic health record: case study of HealthSpace. BMJ 2010, 341:C5814.

31. Osborn CY, Mayberry LS, Mulvaney SA, Hess R: Patient web portals to improve diabetes outcomes: a systematic review. Curr Diab Reports 2010, 10:422-435.

32. Snoek FJ, Van Der Ven NCW, Twisk JWR, Hogenelst MHE, Tromp-Wever AME, Van Der Ploeg HM, Heine RJ: Cognitive behavioural therapy (CBT) compared with blood glucose awareness training (BGAT) in poorly controlled Type 1 diabetic patients: long-term effects on $\mathrm{HbA} 1 \mathrm{c}$ moderated by depression. A randomized controlled trial. Diabet Med 2008, 25:1337-1342.

33. van der Ven N, Snoek FJ: Diabetes de baas: ontwikkeling en toepassing van een groepsinterventie, gebaseerd op cognitieve-gedragstherapie voor patiënten met type-i-diabetes. Directieve therapie 2001, 21:87-96.

34. Schwarzer R: Modeling health behavior change: How to predict and modify the adoption and maintenance of health behaviors. Appl Psychol 2008, 57:1-29.

35. Michie S, Ashford S, Sniehotta FF, Dombrowski SU, Bishop A, French DP: A refined taxonomy of behaviour change techniques to help people change their physical activity and healthy eating behaviours: the CALO-RE taxonomy. Psychol Health 2011, 26:1479-1498.

36. Davies MJ, Heller S, Skinner TC, Campbell MJ, Carey ME, Cradock S, Dallosso $H M$, Daly H, Doherty Y, Eaton S: Effectiveness of the diabetes education and self management for ongoing and newly diagnosed (DESMOND) programme for people with newly diagnosed type 2 diabetes: cluster randomised controlled trial. Bmj 2008, 336:491-495

37. Gillett M, Dallosso HM, Dixon S, Brennan A, Carey ME, Campbell MJ, Heller S, Khunti K, Skinner TC, Davies MJ: Delivering the diabetes education and self management for ongoing and newly diagnosed (DESMOND) programme for people with newly diagnosed type 2 diabetes: cost effectiveness analysis. BMJ 2010, 341:C4093.

38. Khunti K, Gray LJ, Skinner T, Carey ME, Realf K, Dallosso H, Fisher H, Campbell M, Heller S, Davies MJ: Effectiveness of a diabetes education and self management programme (DESMOND) for people with newly diagnosed type 2 diabetes mellitus: three year follow-up of a cluster randomised controlled trial in primary care. BMJ 2012, 344:e2333.

39. Leibbrandt AJ, Kiefte-de Jong JC, Hogenelst MH, Snoek FJ, Weijs PJ: Effects of the PRo-active Interdisciplinary Self-MAnagement (PRISMA, Dutch DESMOND) program on dietary intake in type 2 diabetes outpatients: a pilot study. Clin Nutr 2010, 29:199-205.

40. Skinner TC, Carey ME, Cradock S, Dallosso HM, Daly H, Davies MJ, Doherty Y, Heller S, Khunti K, Oliver L: "Educator talk" and patient change: some insights from the DESMOND (Diabetes Education and Self Management for Ongoing and Newly Diagnosed) randomized controlled trial. Diabet Med 2008, 25:1117-1120.

41. Toobert DJ, Hampson SE, Glasgow aR: The summary of diabetes self-care activities measure: results from 7 studies and a revised scale. Diabetes care 2000, 23:943-950.
42. McGuire BE, Morrison TG, Hermanns N, Skovlund S, Eldrup E, Gagliardino J, Kokoszka A, Matthews D, Pibernik-Okanovi-ç M, Rodriguez-Salda + ja J: Short-form measures of diabetes-related emotional distress: the Problem Areas in Diabetes Scale (PAID)-5 and PAID-1. Diabetologia 2010, 53:66-69.

43. Hajos TRS, Pouwer F, Skovlund SE, Den Oudsten BL, Geelhoed-Duijvestijn PHLM, Tack CJ, Snoek FJ: Psychometric and screening properties of the WHO-5 well-being index in adult outpatients with Type 1 or Type 2 diabetes mellitus. Diabet Med 2013, 30:e63-e69.

44. Bech P, Olsen LR, Kjoller M, Rasmussen NK: Measuring well-being rather than the absence of distress symptoms: a comparison of the SF-36 Mental Health subscale and the WHO-5 well-being scale. Int J Methods Psych Res 2003, 12:85-91.

45. Walters SJ, Brazier JE: Comparison of the minimally important difference for two health state utility measures: EQ-5D and SF-6D. Qual Life Res 2005, 14:1523-1532.

46. Herdman M, Gudex C, Lloyd A, Janssen MF, Kind P, Parkin D, Bonsel G, Badia $X$ : Development and preliminary testing of the new five-level version of EQ-5D (EQ-5D-5 L). Qual Life Res 2011, 20:1727-1736.

47. Thoolen BJ, Ridder D, Bensing J, Gorter K, Rutten G: Beyond good intentions: The role of proactive coping in achieving sustained behavioural change in the context of diabetes management. Psychol Health 2009, 24:237-254.

48. Eysenbach G: The law of attrition. J Med Internet Res 2005, 7:e11.

\section{doi:10.1186/1472-6823-13-53}

Cite this article as: van Vugt et al: Web-based self-management with and without coaching for type 2 diabetes patients in primary care: design of a randomized controlled trial. BMC Endocrine Disorders 2013 13:53.

\section{Submit your next manuscript to BioMed Central and take full advantage of:}

- Convenient online submission

- Thorough peer review

- No space constraints or color figure charges

- Immediate publication on acceptance

- Inclusion in PubMed, CAS, Scopus and Google Scholar

- Research which is freely available for redistribution 